\title{
SUFFICIENT CONDITIONS FOR INTEGRAL OPERATOR DEFINED BY BESSEL FUNCTIONS
}

\author{
B. A. FRASIN
}

Abstract. The main object of the present paper is to derive several sufficient conditions for integral operator defined by Bessel functions of the first kind to be convex and strongly convex of given order in the open unit disk.

Mathematics subject classification (2010): 30C45, 30A20, 33C10.

Keywords and phrases: Analytic functions, Convex functions, Bessel functions, Integral operator.

\section{REFERENCES}

[1] A. BARICZ And B. A. Frasin, Univalence of integral operators involving Bessel functions, Applied Mathematics Letters (in press)

[2] D. BREAZ, A convexity property for an integral operator on the class $\mathscr{S}_{\alpha}(\beta)$, Gen. Math., 15, 2-3 (2007), 177-183.

[3] D. BReaZ AND N. BReaZ, Two integral operator, Studia Universitatis Babes-Bolyai, Mathematica, Cluj-Napoca, 3 (2002), 13-21.

[4] D. BReAZ AND H. GÜNEY, The integral operator on the classes $\mathscr{S}_{\alpha}^{*}(b)$ and $\mathscr{C}_{\alpha}(b)$, J. Math. Ineq., 2, 1 (2008), 97-100.

[5] D. Breaz, S.Owa And N. Breaz, A new integral univalent operator, Acta Univ. Apulensis Math., 16 (2008), 11-16.

[6] S. Bulut, A note on the paper of Breaz and Güney, J. Math. Ineq., 2, 4 (2008), 549-553.

[7] B.A. Frasin, Some sunfficient conditions for certain integral operators, J. Math. Ineq., 2, 4 (2008), 527-535.

[8] R. SZÁsz, P. KupÁn, About the univalence of the Bessel functions, Stud. Univ. Babeş-Bolyai Math., 54, 1 (2009), 127-132. 